\title{
Improved Quality of Life Following Addiction Treatment Is Associated with Reductions in Substance Use
}

\author{
Victoria Manning 1,2,*, Joshua B. B. Garfield $\left.{ }^{1,2}{ }^{(}\right)$, Tina Lam ${ }^{1}$, Steve Allsop ${ }^{3}$, Lynda Berends ${ }^{4,5}$, \\ David Best ${ }^{6}$, Penny Buykx ${ }^{7}$, Robin Room ${ }^{8,9}$ and Dan I. Lubman $1,2 \mathbb{D}$ \\ 1 Monash Addiction Research Centre, Eastern Health Clinical School, Monash University, 110 Church Street, \\ Richmond, Victoria 3121, Australia \\ 2 Turning Point, Eastern Health, 110 Church Street, Richmond, Victoria 3121, Australia \\ 3 National Drug Research Institute, Curtin University, 2 Building 609, Curtin University, 7 Parker Place, \\ Bentley 6102, Australia \\ 4 TRACE Research, 1/209 Nicholson St, Footscray, Victoria 3011, Australia \\ 5 National Drug and Alcohol Research Centre, University of New South Wales, Sydney 2052, Australia \\ 6 Department of Law, Criminology, and Community Justice, Sheffield Hallam University, Howard St, \\ Sheffield S1 1WB, UK \\ 7 School of Humanities and Social Science, University of Newcastle, University Drive, \\ Callaghan 2308, Australia \\ 8 Centre for Alcohol Policy Research, La Trobe University, Bundoora, Victoria 3086 Australia \\ 9 Centre for Social Research on Alcohol \& Drugs, Department of Public Health Sciences, Stockholm University, \\ SE - 10691 Stockholm, Sweden \\ * Correspondence: victoria.manning@monash.edu; Tel.: +61-3-8413-8274
}

Received: 13 August 2019; Accepted: 5 September 2019; Published: 6 September 2019

\begin{abstract}
People seeking treatment for substance use disorders (SUD) ultimately aspire to improve their quality of life (QOL) through reducing or ceasing their substance use, however the association between these treatment outcomes has received scant research attention. In a prospective, multi-site treatment outcome study ('Patient Pathways'), we recruited 796 clients within one month of intake from 21 publicly funded addiction treatment services in two Australian states, $555(70 \%)$ of whom were followed-up 12 months later. We measured QOL at baseline and follow-up using the WHOQOL-BREF (physical, psychological, social and environmental domains) and determined rates of "SUD treatment success" (past-month abstinence or a statistically reliable reduction in substance use) at follow-up. Mixed effects linear regression analyses indicated that people who achieved SUD treatment success also achieved significantly greater improvements in QOL, relative to treatment non-responders (all four domains $p<0.001$ ). Paired $t$-tests indicated that non-responders significantly improved their social $(p=0.007)$ and environmental $(p=0.033)$ QOL; however, their psychological $(p=0.088)$ and physical ( $p=0.841)$ QOL did not significantly improve. The findings indicate that following treatment, QOL improved in at least some domains, but that reduced substance use was associated with both stronger and broader improvements in QOL. Addressing physical and psychological co-morbidities during treatment may facilitate reductions in substance use.
\end{abstract}

Keywords: quality of life; substance use treatment; substance use disorder; reduced substance use; abstinence; treatment outcome; addiction; alcohol and drugs

\section{Introduction}

Previous outcome studies have consistently reported high rates of cessation or substantial reduction in substance use following treatment [1-9]. However, substance use disorders (SUD) affect 
multiple other areas of health and psychosocial functioning, and improvement in these domains is also a common goal of treatment. As noted by Ray, Lim, and Shoptaw [10], "A vague but universal objective among individuals entering addiction treatment is to 'get their life back'". Indeed, a panel of treatment and research experts convened by the US National Institute on Drug Abuse (NIDA) in 2009 recommended that SUD treatment outcome research seek to measure a number of other domains, specifically, craving, psychosocial functioning, self-efficacy, quality of life (QOL), and social support [11]. However, Tiffany et al. [11] observed that, at that time, addiction research lagged behind other biomedical fields in terms of evaluating QOL outcomes.

Nevertheless, several major treatment outcome studies have included measures of health-related QOL, such as the 12-item [12] or 36-item versions of the Short Form Health Survey [13] (SF-12 and SF-36, respectively). The Australian Treatment Outcome Study (ATOS) of people entering treatment for heroin dependence found improvements in SF-12 physical health, which reached levels similar to general population norms one year following treatment entry, whilst psychological health remained below population norms despite improving [14-16]. Similarly, in the UK Drug Treatment Outcomes Research Study (DTORS), changes in SF-12 scores indicated improvements in psychological health 3-5 months after treatment, though again, with mean scores remaining below general population norms, whilst mean physical health scores, already similar to general population norms at baseline, remained unchanged [8]. Other studies have observed improvements in physical and psychological well-being after treatment using measures other than QOL scales $[1,3,5,7]$.

Another widely-used QOL measure is the brief version of the World Health Organization Quality of Life scale (WHOQOL-BREF) [17] which, in addition to physical and mental QOL, also assesses social, and environmental (e.g., financial resources; opportunities for leisure and skill-acquisition) QOL. Significant improvements in all four QOL domains have been reported following commencement of treatment in several studies of OST for opioid use disorder [18-21] and also at 6- and 12-month follow-ups in a large alcohol use disorder treatment study [22]. In another study focused on women receiving treatment for SUD, all WHOQOL-BREF domains except social QOL significantly improved 6 months after treatment intake [23].

Poor QOL as a result of a substance-using lifestyle is often the impetus for help-seeking. Numerous studies report that negative social consequences of substance use are often major reasons for treatment-seeking [24-27], with one study identifying that they were a stronger predictor of entering treatment than dependence symptoms [27]. Medical and psychological problems have also been reported as either predictors, or common precipitators, of SUD treatment-seeking in several studies $[24,25,27]$. The corollary is that improvements in social, psychological, and physical QOL are often likely to be an important outcome for clients, and one which may help them maintain reductions in substance use over the long term. However, it remains unclear whether these two types of outcomes (reduced substance use and improved QOL) are related to or dependent on each other. Few studies have examined these associations using measures specifically designed to assess QOL. In DTORS, those who reported past 3-month abstinence from illicit drugs (other than cannabis) at a 33-month follow-up had nearly five times the odds of an improvement in SF-36 psychological health score greater than one standard deviation (SD) above the total sample's average improvement [9]. In contrast, Tracy et al. [23] found relatively little evidence that substance use at follow-up was associated with QOL outcomes on the WHOQOL-BREF, with abstinence from alcohol at follow-up and environmental QOL being the only significant association.

Kiluk et al. [28] recently challenged the value of using global measures of psychosocial functioning in addiction treatment research and suggested measures of specific wellbeing/psychosocial consequences that can be causally attributed to substance use are more clinically meaningful. However, it may be difficult to distinguish between consequences that are clearly substance use-related, indirectly related, or unrelated, especially over the long time-frames of many treatment outcome studies. Indeed, the paucity of studies addressing this question precludes us from drawing any conclusion on whether or not QOL is related to other clinically meaningful outcomes. Thus, to advance the 
literature around the validity of general QOL scales as outcome measures, we analysed data from a large Australian treatment outcome study to examine whether reducing/ceasing substance use was associated with improvements on the four QOL domains measured by the WHOQOL-BREF. We hypothesised that participants who reduced/ceased use of their primary drug of concern (PDOC) would show larger improvements in QOL than those who did not reliably reduce their PDOC use ("treatment non-responders"). Nonetheless, we also explored whether there were still detectable improvements in QOL among treatment non-responders, despite their continued substance use.

\section{Methods}

'Patient Pathways' was a prospective treatment outcome study. The participants, measures, and procedures have been described extensively elsewhere [29-31] and, for the sake of brevity, only aspects pertinent for understanding the current analyses are summarised below. Ethics approval was provided by the Eastern Health Human Research Ethics Committee (E17/1112), Monash University Human Research Ethics Committee (201200020) and Curtin University (HR11/2012).

Participants and setting: 796 participants aged $\geq 18$ years, who had commenced treatment within the past month, were recruited from 21 different specialist alcohol/drug services across 37 different sites in Victoria and Western Australia (WA) including acute withdrawal, residential rehabilitation and outpatient settings. Baseline interviews were conducted between January 2012 and January 2013 and $555(70 \%)$ participants completed a 1-year follow-up. Due to missing data regarding either substance use or QOL, the present analyses included 536 participants (for physical and psychological QOL) or 535 participants (for social and environmental QOL).

Relevant measures: At both baseline and follow-up, researchers administered a battery of questionnaires which included measures of demographic characteristics, substance use, and QOL. Participants were asked to identify their PDOC and frequency of use of all licit and illicit substances in the past 30 days was measured using the ASSIST [32]. QOL was measured using the 24 items measuring the four domains of the WHOQOL-BREF (physical, psychological, social and environmental). The WHOQOL-BREF has been shown to have cross-cultural applicability and strong reliability and validity in both general population and physical and mental health treatment samples [17], as well as an alcohol use disorder treatment sample [22]. Australian general population norms were published for the WHOQOL-BREF in 2006 [33].

Analyses: SUD treatment success was defined as achieving either of two outcomes: abstinence from the PDOC (the predominant treatment goal for $74.0 \%$ of participants) in the 30 days prior to follow-up, or a statistically-reliable reduction in days of PDOC use in the past month at follow-up, relative to baseline. Reliable change criteria (RCC) were calculated using the Jacobson and Truax [34] formula, utilising reliability indices reported by Ryan et al. [35]. Further details of these calculations are provided in Supplementary Materials. Differences in QOL outcomes at follow-up between participants who achieved treatment success and non-responders were analysed using Stata version 14. Mixed effects linear regression was undertaken separately for each WHOQOL-BREF domain, assessing the time $\times$ treatment success interaction to test whether participants achieving SUD treatment success showed a greater change in WHOQOL-BREF scores between baseline and follow-up, relative to SUD treatment non-responders. Multivariate analysis adjusted for age, sex, PDOC, primary index treatment (PIT) type at baseline (i.e., outpatient, withdrawal management, or residential rehabilitation), whether or not the PIT was ended early, and time between baseline and follow-up. Separate paired $t$-tests were used to test whether changes in WHOQOL-BREF scores were significant in treatment responders and non-responders. One-sample $t$-tests were used to test whether QOL scores differed significantly from general population means. Independent samples $t$-tests were used to compare SUD treatment responders' WHOQOL-BREF scores to those of SUD treatment non-responders at baseline and at follow-up. 


\section{Results}

Table 1 describes baseline characteristics of the 536 participants included in these analyses. Mean scores on all domains of the WHOQOL-BREF were between 1 to 2 SDs below the Australian general population mean (physical: $t(535)=-24.03$; psychological: $t(535)=-27.52$; social: $t(534)=26.85$; environmental: $t(534)=-19.44$; all $p<0.001)$. Follow-ups occurred a mean of 381.1 days $(\mathrm{SD}=71.9)$ after the baseline interview, and at the time of the follow-up, $66.1 \%$ of participants had completed their PIT, 5.6\% were still engaged with it, and $28.2 \%$ had left or been expelled from their PIT prior to completion. Half $(51.9 \%)$ met the criterion for SUD treatment success (38.4\% because they were abstinent at follow-up, 13.4\% because they reliably reduced number of days of use of the PDOC, despite not being abstinent). Participants missing from analyses due to either loss to follow-up or missing QOL or treatment outcome data $(n=260)$ were significantly younger (mean $=35.00 \pm 10.79$ versus mean $=$ $38.16 \pm 10.64, t(789)=-3.897, p<0.001)$; and more likely to have amphetamines, and less likely to have alcohol, as their PDOC (Pearson $\chi^{2}=12.784, p=0.012$ ). Participants recruited from residential rehabilitation $(41.7 \%)$ and acute withdrawal $(33.0 \%)$ were more likely to be missing from analyses than those recruited from outpatient settings $\left(22.0 \%, \chi^{2}=19.802, p<0.001\right)$. There were no differences in gender between those included in and those missing from analyses $\left(\chi^{2}=1.553, p=0.213\right)$ nor in any domain of baseline WHOQOL-BREF scores (all $p>0.05$ ).

Table 1. Baseline demographic and clinical characteristics of participants.

\begin{tabular}{|c|c|c|}
\hline Variable & & Value \\
\hline Age (years), mean (SD) & & $38.2(10.6)$ \\
\hline \multirow{3}{*}{ Sex } & Male & $324(60.4 \%)$ \\
\hline & Female & $210(39.2 \%)$ \\
\hline & Missing & $2(0.4 \%)$ \\
\hline \multirow{5}{*}{ Primary drug of concern (PDOC) } & Alcohol & $268(50.0 \%)$ \\
\hline & Cannabis & $84(15.7 \%)$ \\
\hline & Opiates & $81(15.1 \%)$ \\
\hline & Amphetamines & $90(16.8 \%)$ \\
\hline & Other & $13(2.4 \%)$ \\
\hline \multirow{3}{*}{ Primary index treatment (PIT) } & Outpatient & $167(31.2 \%)$ \\
\hline & Acute withdrawal & $235(43.8 \%)$ \\
\hline & Residential rehabilitation & $134(25.0 \%)$ \\
\hline \multirow{2}{*}{ Physical quality of life, mean (SD) } & WHOQOL-BREF numerical score & $52.4(20.3)$ \\
\hline & Australian population z-score ${ }^{1}$ & $-1.16(1.12)$ \\
\hline \multirow{2}{*}{$\begin{array}{l}\text { Psychological quality of life, } \\
\text { mean (SD) }\end{array}$} & WHOQOL-BREF numerical score & $45.3(21.3)$ \\
\hline & Australian population z-score ${ }^{1}$ & $-1.81(1.52)$ \\
\hline \multirow{2}{*}{ Social quality of life, mean (SD) } & WHOQOL-BREF numerical score & $43.4(24.2)$ \\
\hline & Australian population z-score ${ }^{1}$ & $-1.55(1.33)$ \\
\hline \multirow{2}{*}{$\begin{array}{l}\text { Environmental quality of life, } \\
\text { mean (SD) }\end{array}$} & WHOQOL-BREF numerical score & $59.1(19.0)$ \\
\hline & Australian population z-score ${ }^{1}$ & $-1.23(1.46)$ \\
\hline
\end{tabular}

WHOQOL-BREF: World Health Organization Quality of Life Scale (Brief version). ${ }^{1}$ WHOQOL-BREF scores expressed as Australian general population standard deviations from the Australian population mean, according to normative data published by Hawthorne et al. [33].

Table 2 shows WHOQOL-BREF scores for each QOL domain separately for treatment responders and non-responders. Both groups had similar scores across all four domains at baseline. Among treatment responders, improvements in QOL were significant for all four domains. The increases in score were equivalent to improvements of $0.73,1.07,0.92$, and 0.75 general population SDs for the physical, psychological, social, and environmental domains, respectively. Thus, at follow-up, their mean scores were all within one $\mathrm{SD}$ of population norms (physical: $-0.46, \mathrm{SD}=1.19$; psychological: $-0.77, \mathrm{SD}=1.50$; social: $-0.72, \mathrm{SD}=1.43$; environmental: $-0.49, \mathrm{SD}=1.26)$. Nevertheless, these scores 
were still significantly lower than general population norms (physical: $t(277)=-6.45$; psychological: $t(277)=-8.57$; social: $t(277)=-8.35$; environmental: $t(277)=6.51$; all $p<0.001)$. Among treatment responders, non-abstinent participants who reliably reduced their PDOC use showed similar QOL improvements to those who achieved abstinence at follow-up (see Supplementary Materials, including Figure S1).

For SUD treatment non-responders, there were no significant changes in physical or psychological QOL scores between baseline and follow-up. While increases in social and environmental QOL were statistically significant in SUD treatment non-responders, the magnitude of improvement was equivalent to only 0.24 and 0.18 Australian general population SDs, respectively. Thus, at follow-up, non-responders' mean scores were still more than one SD below general population norms for all domains (physical: $-1.12, \mathrm{SD}=1.13, t(257)=-15.83$; psychological: $-1.60, \mathrm{SD}=1.54, t(257)=-16.63$; social: $-1.21, \mathrm{SD}=1.35, t(257)=-14.38$; environmental: $-1.03, \mathrm{SD}=1.38, t(257)=-11.94$; all $p<0.001)$. As shown in Table 2, linear regression analyses found that the time $x$ treatment success interactions were significant for all QOL domains, confirming that improvements in QOL were significantly larger in treatment responders than in non-responders.

Further exploratory repeated measures ANOVA analyses examined whether these interactions were consistent across PDOC (i.e., alcohol versus illicit drug). There were no significant three-way interactions between PDOC, time, and treatment success for environmental, social or physical QOL, but there was a significant three-way interaction for psychological QOL $(F(1,532)=4.874, p=0.028$, $\left.\eta^{2}{ }_{p}=0.009\right)$. This interaction is explored further in Supplementary Materials. Importantly, despite this three-way interaction, the two-way interaction between time and treatment success was significant in both PDOC groups (see Supplementary Results, including Figure S2), suggesting that the main finding (i.e., that improvement in psychological QOL was greater in treatment responders than in non-responders) was consistent, despite this association being stronger in those with alcohol as their PDOC. In addition, there were no 2-way interactions between PDOC and time, suggesting no general effect of PDOC on changes in QOL over time. 
Table 2. Changes in WHOQOL-BREF scores between baseline and follow-up, compared between those who achieved treatment success vs. those who did not, with results of linear regression models testing the time $x$ treatment success interactions.

\begin{tabular}{|c|c|c|c|c|c|c|c|c|c|c|}
\hline \multirow{2}{*}{ QOL Domain $^{3}$} & \multirow{2}{*}{$\begin{array}{l}\text { Treatment } \\
\text { Success }\end{array}$} & \multirow{2}{*}{$\begin{array}{l}\text { Baseline } \\
\text { Mean (SD) }\end{array}$} & \multirow{2}{*}{$\begin{array}{l}\text { Follow-up } \\
\text { Mean (SD) }\end{array}$} & \multirow{2}{*}{$\begin{array}{l}P \text {-Value for Within-Category } \\
\text { Change from Baseline to } \\
\text { Follow-up }{ }^{1}\end{array}$} & \multicolumn{3}{|c|}{ Unadjusted } & \multicolumn{3}{|c|}{ Adjusted $^{2}$} \\
\hline & & & & & $\begin{array}{l}\text { Estimated } \\
\text { Difference }\end{array}$ & $95 \% \mathrm{CI}$ & $p$-Value & $\begin{array}{l}\text { Estimated } \\
\text { Difference }\end{array}$ & $95 \% \mathrm{CI}$ & $p$-Value \\
\hline \multirow{2}{*}{$\begin{array}{c}\text { Physical } \\
\text { between-groups } \\
p \text {-value }\end{array}$} & $\begin{array}{l}\text { No } \\
\text { Yes }\end{array}$ & $\begin{array}{l}53.0(18.5) \\
51.9(21.8)\end{array}$ & $\begin{array}{l}53.3(20.5) \\
65.1(21.6)\end{array}$ & $\begin{array}{c}0.841 \\
<0.001\end{array}$ & 12.99 & $9.43-16.56$ & $<0.001$ & 13.22 & $9.66-16.78$ & $<0.001$ \\
\hline & & 0.504 & $<0.001$ & & & & & & & \\
\hline \multirow{2}{*}{$\begin{array}{c}\text { Psychological } \\
\text { between-groups } \\
p \text {-value }\end{array}$} & $\begin{array}{l}\text { No } \\
\text { Yes }\end{array}$ & $\begin{array}{l}45.8(19.9) \\
44.8(22.5)\end{array}$ & $\begin{array}{l}48.2(21.6) \\
59.8(21.0)\end{array}$ & $\begin{array}{c}0.088 \\
<0.001\end{array}$ & 12.65 & $8.73-16.58$ & $<0.001$ & 12.98 & $9.06-16.89$ & $<0.001$ \\
\hline & & 0.588 & $<0.001$ & & & & & & & \\
\hline \multirow{2}{*}{$\begin{array}{c}\text { Social } \\
\text { between-groups } \\
p \text {-value }\end{array}$} & $\begin{array}{l}\text { No } \\
\text { Yes }\end{array}$ & $\begin{array}{l}45.2(23.4) \\
41.7(24.8)\end{array}$ & $\begin{array}{l}49.6(24.5) \\
58.5(26.0)\end{array}$ & $\begin{array}{c}0.007 \\
<0.001\end{array}$ & 12.37 & $7.63-17.11$ & $<0.001$ & 12.91 & $8.20-17.62$ & $<0.001$ \\
\hline & & 0.101 & $<0.001$ & & & & & & & \\
\hline \multirow{2}{*}{$\begin{array}{c}\text { Environmental } \\
\text { between-groups } \\
p \text {-value }\end{array}$} & $\begin{array}{l}\text { No } \\
\text { Yes }\end{array}$ & $\begin{array}{l}59.3(18.7) \\
59.0(19.3)\end{array}$ & $\begin{array}{l}61.7(18.0) \\
68.7(16.4)\end{array}$ & $\begin{array}{c}0.033 \\
<0.001\end{array}$ & 7.24 & $3.84-10.64$ & $<0.001$ & 7.38 & $3.96-10.80$ & $<0.001$ \\
\hline & & 0.816 & $<0.001$ & & & & & & & \\
\hline
\end{tabular}

QOL: quality of life. Estimated difference refers to estimated difference in effect between the abstinent group, compared to non-abstinent, group over time. ${ }^{1} p$ value for change from baseline to follow-up in paired-samples $t$-tests conducted separately within each treatment success category. ${ }^{2}$ Adjusted for age, sex, time between baseline and follow-up, primary index treatment (PIT) type, whether or not PIT was ceased early (i.e., neither completed as planned nor still continuing at follow-up), and primary drug of concern. ${ }^{3}$ For comparison, Australian general population norms published by Hawthorne et al. are 73.5 (18.1), 70.6 (14.0), 71.5 (18.2), and 75.1 (13.0) for physical, psychological, social, and environmental domains, respectively. 


\section{Discussion}

Consistent with previous findings of improved QOL following engagement with treatment for SUD $[8,16,18-23]$, we observed improvements in all four domains of the WHOQOL-BREF at the one-year follow-up. However, for physical and psychological QOL, these improvements were only significant in participants who substantially reduced their frequency of use of, or ceased using, their PDOC. Although SUD treatment non-responders showed significant increases in social and environmental QOL, these were significantly smaller than the increases shown by SUD treatment responders. In contrast to Kiluk et al.'s [28] proposition that outcomes indexed by general measures of well-being were relatively unrelated to substance use outcomes, these findings suggest that outcomes measured by the WHOQOL-BREF were robustly related to substance use outcomes, suggesting that this instrument offers important and relevant information about treatment outcomes.

While some previous reports found associations between improved psychological well-being and substance use outcomes [9,36-38], several studies have reported that these associations are weak, and are also generally weak or absent for indicators of physical and social QOL [23,36-39]. However, of the reports suggesting weak or absent associations between changes in well-being and substance use following treatment, only one [23] used a measure designed specifically to measure QOL, and this was conducted with a modest-sized, female-only sample. Moreover, these previous studies were based in the US, and it is unclear whether differences between the US and Australian treatment systems, or more broadly (e.g., differences in culture or patterns of substance use) may explain why we found much stronger evidence for these associations than these previous studies.

Given that this was a naturalistic non-randomised cohort study with only one follow-up in which QOL and substance use outcomes were assessed at the same time, we cannot draw causal conclusions regarding our findings. Our ability to interpret these findings is also limited by the fact that $30 \%$ of the baseline sample was lost to follow-up. Thus, our analyses might overestimate actual improvements in $\mathrm{QOL}$, and this may bias our findings regarding the degree of association between these improvements and substance use outcomes. Moreover, participants missing from these analyses were younger than those included in these analyses, and differed from those included in terms of PDOC and PIT, and this may also bias our analyses and/or limit generalisability. Moreover, improvements in QOL may partly reflect regression to the mean, particularly given that people are likely to be at a particularly "low point" in their lives when entering SUD treatment. Thus, in the absence of a non-treatment control group, the improvements in social and environmental QOL in treatment non-responders cannot reliably be attributed to SUD treatment. While it could be argued that regression to the mean in treatment responders should be reflected in all four QOL domains, not just social and environmental, their lack of a significant improvement in physical and psychological QOL may be due to the fact that these domains are more intrinsically related to substance use. One final limitation is that psychiatric diagnosis was not assessed, and therefore its impact on changes in QOL could not be examined.

Despite these caveats, our findings are suggestive of two similarly plausible explanations (which are not mutually exclusive, and indeed may operate together in a mutually reinforcing manner). One is that substance use (directly and/or indirectly) negatively impacts, and/or prevents improvements in, QOL. Thus, those who reduce their substance use are "freed" from these negative impacts and are more likely to experience improvements in QOL. This would suggest that treatments effective at reducing substance use (i.e., psychotherapeutic interventions, peer support/mutual aid, pharmacotherapy, and residential rehabilitation) are also inherently beneficial to QOL. This emphasises the importance of increasing the availability of, and facilitating clients' access to, these treatments, as well as finding ways to maximise rates of treatment completion [31]. Nevertheless, the significant (albeit small) improvements in social and environmental QOL seen among treatment non-responders suggest that treatment may be beneficial even to those who achieve little or no change in their substance use. The unexpected improvements in social QOL could be attributed to the fostering of new social relationships, including connecting with others in SUD treatment or mutual aid/peer support (attended by $48.6 \%$ [31]), and/or by strengthening social support or pre-existing relationships by virtue of the participant entering treatment 
to address their SUD. Moreover, by being in treatment participants could have been referred to social and welfare services (e.g., housing, employment agencies etc.), leading to improved financial security, safety, comfort and convenience of their living environment, and improved access to resources and meaningful activities, thereby accounting for an improved environmental QOL.

The alternative explanation is that experiencing improvements in QOL facilitates, or motivates, reductions in substance use. For example, in line with the self-medication hypothesis [40], participants may have continued using substances as a coping mechanism for managing psychological distress, pain, or severe/complex psychosocial issues, and may become much more likely to reduce their substance use only after finding alternate solutions that improve their QOL. This would suggest that, for clients with poor physical and/or psychological wellbeing (a substantial proportion of the treatment-seeking population) and with poor QOL more generally, finding solutions to these problems would often be necessary to achieve reductions in substance use. Indeed, Hunt and Azrin's [41] small trial of the "community reinforcement" approach, an intensive approach aimed at improving social and environmental QOL, contingent on abstaining from alcohol, found that it led to high rates of abstinence among alcohol-dependent men. This also emphasises the importance of integrated care and referral between addiction treatment and other mental health, medical, social (e.g., housing and employment) services, and peer support, to achieve not only improvements in these domains, but potentially in substance use as well. Nonetheless, the influence of other variables (e.g., demographic and clinical characteristics) on changes in QOL, particularly whether other factors moderate or mediate associations between treatment success and improvement in quality of life, warrants examination in future research.

Supplementary Materials: Supplementary methods and results are available online at http://www.mdpi.com/ 2077-0383/8/9/1407/s1, including Figure S1: Scores on each WHOQOL-BREF domain at baseline and follow-up among those who were abstinent at follow-up; those who reliably reduced use of their primary drug of concern (PDOC), but were not abstinent at follow-up; and those who did not reliably reduce the frequency of use of their PDOC, Figure S2: Changes in psychological QOL between baseline and follow-up among treatment responders (solid lines) and non-responders (dashed lines), shown separately for those with alcohol as PDOC (top panel), and those with any other drug as their PDOC (bottom panel).

Author Contributions: L.B., P.B., and R.R. were involved in conceiving the study, designing its methodology, and acquiring funding for it. D.B., D.I.L., L.B., P.B., S.A., T.L., and V.M. supervised data collection. V.M. and J.B.B.G. conceived the specific aims and hypotheses analysed in this manuscript, oversaw and interpreted these analyses, and wrote the initial draft. All authors were involved in reviewing and editing the final version of this manuscript.

Funding: This research was funded by the Commonwealth Department of Health, Australia.

Acknowledgments: We thank the participants and treatment service staff that supported the project. We would like to acknowledge others members of the research team who assisted with designing and overseeing the project, recruiting participants, and collecting data, including Seraina Agramunt, Julia Butt, Sue Carruthers, Dina Eleftheriadis, Sarah Flynn, Jodie Grigg, Cherie Heilbronn, Barbara Hunter, Klaudia Jones, Shraddha Kashyap, Jessica Killian, Andrew Larner, Belinda Lloyd, Melaine McAleer, Terence McCann, Janette Mugavin, Vijay Rawat, and Terry Slomp. We also acknowledge Cathy Martin for assistance with statistical analyses.

Conflicts of Interest: Dan I. Lubman has provided consultancy advice to Lundbeck and Indivior, and has received travel support and speaker honoraria from Astra Zeneca, Janssen, Lundbeck, Shire and Servier. The authors have no other conflicts of interest to declare. The Australian Commonwealth Department of Health, which funded this study, played no role in the design of the study or in the collection, analysis, and interpretation of data, and had no role in the preparation of this manuscript.

\section{References}

1. Comiskey, C.; Kelly, P.; Leckey, Y.; McCullough, L.; O’Duill, B.; Stapleton, R.; White, E. The ROSIE Study: Drug Treatment Outcomes in Ireland; Stationery Office: Dublin, Ireland, 2009.

2. Darke, S.; Marel, C.; Slade, T.; Ross, J.; Mills, K.L.; Teesson, M. Patterns and Correlates of Sustained Heroin Abstinence: Findings From the 11-Year Follow-Up of the Australian Treatment Outcome Study. J. Stud. Alcohol Drugs 2015, 76, 909-915. [CrossRef]

3. Gossop, M.; Marsden, J.; Stewart, D. Treatment outcomes of stimulant misusers: One year follow-up results from the national treatment outcome research study (NTORS). Addict. Behav. 2000, 25, 509-522. [CrossRef] 
4. Gossop, M.; Marsden, J.; Stewart, D.; Kidd, T. Changes in use of crack cocaine after drug misuse treatment: 4-5 year follow-up results from the National Treatment Outcome Research Study (NTORS). Drug Alcohol Depend. 2002, 66, 21-28. [CrossRef]

5. Gossop, M.; Marsden, J.; Stewart, D.; Kidd, T. The National Treatment Outcome Research Study (NTORS): 4-5 year follow-up results. Addiction 2003, 98, 291-303. [CrossRef]

6. Gossop, M.; Marsden, J.; Stewart, D.; Rolfe, A. Patterns of drinking and drinking outcomes among drug misusers. 1-year follow-up results. J. Subst. Abuse Treat. 2000, 19, 45-50. [CrossRef]

7. Hubbard, R.L.; Craddock, S.G.; Anderson, J. Overview of 5-year followup outcomes in the drug abuse treatment outcome studies (DATOS). J. Subst. Abuse Treat. 2003, 25, 125-134. [CrossRef]

8. Jones, A.; Donmall, M.; Millar, T.; Moody, A.; Weston, S.; Anderson, T.; Gittins, M.; Abeywardana, V.; D'Souza, J. The Drug Treatment Outcomes Research Study (DTORS): Final Outcomes Report, 3rd ed.; Home Office: London, UK, 2009.

9. McKeganey, N.; Bloor, M.; McIntosh, J.; Neale, J. Key Findings from the Drug Outcome Research in Scotland (DORIS) Study; University of Glasgow Centre for Drug Misuse Research: Glasgow, Scotland, 2008.

10. Ray, L.A.; Lim, A.C.; Shoptaw, S. What defines a clinically meaningful outcome in the treatment of substance use disorders: 'Getting your life back'. Addiction 2019, 114, 18-20. [CrossRef]

11. Tiffany, S.T.; Friedman, L.; Greenfield, S.F.; Hasin, D.S.; Jackson, R. Beyond drug use: A systematic consideration of other outcomes in evaluations of treatments for substance use disorders. Addiction 2012, 107, 709-718. [CrossRef]

12. Ware, J., Jr.; Kosinski, M.; Keller, S.D. A 12-Item Short-Form Health Survey: Construction of scales and preliminary tests of reliability and validity. Med. Care 1996, 34, 220-233. [CrossRef]

13. Ware, J.E., Jr.; Sherbourne, C.D. The MOS 36-item short-form health survey (SF-36). I. Conceptual framework and item selection. Med. Care 1992, 30, 473-483. [CrossRef]

14. Darke, S.; Ross, J.; Teesson, M. The Australian Treatment Outcome Study (ATOS): What have we learnt about treatment for heroin dependence? Drug Alcohol Rev. 2007, 26, 49-54. [CrossRef]

15. Teesson, M.; Mills, K.; Ross, J.; Darke, S.; Williamson, A.; Havard, A. The impact of treatment on 3 years' outcome for heroin dependence: Findings from the Australian Treatment Outcome Study (ATOS). Addiction 2008, 103, 80-88. [CrossRef]

16. Teesson, M.; Ross, J.; Darke, S.; Lynskey, M.; Ali, R.; Ritter, A.; Cooke, R. One year outcomes for heroin dependence: Findings from the Australian Treatment Outcome Study (ATOS). Drug Alcohol Depend. 2006, 83, 174-180. [CrossRef]

17. Skevington, S.M.; Lotfy, M.; O'Connell, K.A.; Group, W. The World Health Organization's WHOQOL-BREF quality of life assessment: Psychometric properties and results of the international field trial. A report from the WHOQOL group. Qual. Life Res. 2004, 13, 299-310. [CrossRef]

18. Baharom, N.; Hassan, M.R.; Ali, N.; Shah, S.A. Improvement of quality of life following 6 months of methadone maintenance therapy in Malaysia. Subst. Abuse Treat. Prev. Policy. 2012, 7, 32. [CrossRef]

19. Dhawan, A.; Chopra, A. Does buprenorphine maintenance improve the quality of life of opioid users? Indian J. Med. Res. 2013, 137, 130-135.

20. Feelemyer, J.P.; Jarlais, D.C.D.; Arasteh, K.; Phillips, B.W.; Hagan, H. Changes in quality of life (WHOQOL-BREF) and addiction severity index (ASI) among participants in opioid substitution treatment (OST) in low and middle income countries: An international systematic review. Drug Alcohol Depend. 2014, 134, 251-258. [CrossRef]

21. Wang, P.W.; Wu, H.C.; Yen, C.N.; Yeh, Y.C.; Chung, K.S.; Chang, H.C.; Yen, C.F. Change in Quality of Life and Its Predictors in Heroin Users Receiving Methadone Maintenance Treatment in Taiwan: An 18-Month Follow-Up Study. Am. J. Drug Alcohol Abuse 2012, 38, 213-219. [CrossRef]

22. Kirouac, M.; Stein, E.R.; Pearson, M.R.; Witkiewitz, K. Viability of the World Health Organization quality of life measure to assess changes in quality of life following treatment for alcohol use disorder. Qual. Life Res. 2017, 26, 2987-2997. [CrossRef]

23. Tracy, E.M.; Laudet, A.B.; Min, M.O.; Kim, H.; Brown, S.; Jun, M.K.; Singer, L. Prospective patterns and correlates of quality of life among women in substance abuse treatment. Drug Alcohol Depend. 2012, 124, 242-249. [CrossRef] 
24. Marlowe, D.B.; Merikle, E.P.; Kirby, K.C.; Festinger, D.S.; McLellan, A.T. Multidimensional assessment of perceived treatment-entry pressures among substance abusers. Psychol. Addict. Behav. 2001, 15, 97-108. [CrossRef]

25. Orford, J.; Kerr, C.; Copello, A.; Hodgson, R.; Alwyn, T.; Black, R.; Smith, M.; Thistlethwaite, G.; Westwood, A.; Slegg, G. Why people enter treatment for alcohol problems: Findings from UK Alcohol Treatment Trial pre-treatment interviews. J. Subst. Use 2006, 11, 161-176. [CrossRef]

26. Tsogia, D.; Copello, A.; Orford, J. Entering treatment for substance misuse: A review of the literature. J. Mental Health 2001, 10, 481-499. [CrossRef]

27. Weisner, C.; Matzger, H. A prospective study of the factors influencing entry to alcohol and drug treatment. J. Behav. Health Serv. Res. 2002, 29, 126-137. [CrossRef]

28. Kiluk, B.D.; Fitzmaurice, G.M.; Strain, E.C.; Weiss, R.D. What defines a clinically meaningful outcome in the treatment of substance use disorders: Reductions in direct consequences of drug use or improvement in overall functioning? Addiction 2019, 114, 9-15. [CrossRef]

29. Lubman, D.; Manning, V.; Best, D.; Berends, L.; Mugavin, J.; Lloyd, B.; Lam, T.; Garfield, J.; Buykx, P.; Matthews, S.; et al. A Study of Patient Pathways in Alcohol and Other Drug Treatment; Turning Point: Melbourne, Australia, 2014.

30. Lubman, D.I.; Garfield, J.B.B.; Manning, V.; Berends, L.; Best, D.; Mugavin, J.M.; Lam, T.; Buykx, P.; Larner, A.; Lloyd, B.; et al. Characteristics of individuals presenting to treatment for primary alcohol problems versus other drug problems in the Australian patient pathways study. BMC Psychiatry 2016, 16, 250. [CrossRef]

31. Manning, V.; Garfield, J.B.B.; Best, D.; Berends, L.; Room, R.; Mugavin, J.; Larner, A.; Lam, T.; Buykx, P.; Allsop, S.; et al. Substance use outcomes following treatment: Findings from the Australian Patient Pathways Study. Aust. N. Z. J. Psychiatry 2017, 51, 177-189. [CrossRef]

32. WHO ASSIST Working Group. The Alcohol, Smoking and Substance Involvement Screening Test (ASSIST): Development, reliability and feasibility. Addiction 2002, 97, 1183-1194. [CrossRef]

33. Hawthorne, G.; Herrman, H.; Murphy, B. Interpreting the WHOQOL-Brèf: Preliminary Population Norms and Effect Sizes. Soc. Indic. Res. 2006, 77, 37-59. [CrossRef]

34. Jacobson, N.S.; Truax, P. Clinical significance: A statistical approach to defining meaningful change in psychotherapy research. J. Consult. Clin. Psychol. 1991, 59, 12-19. [CrossRef]

35. Ryan, A.; Holmes, J.; Hunt, V.; Dunlop, A.; Mammen, K.; Holland, R.; Sutton, Y.; Sindhusake, D.; Rivas, G.; Lintzeris, N. Validation and implementation of the Australian Treatment Outcomes Profile in specialist drug and alcohol settings. Drug Alcohol Rev. 2014, 33, 33-42. [CrossRef]

36. Kosten, T.R.; Rounsaville, B.J.; Kleber, H.D. Multidimensionality and prediction of treatment outcome in opioid addicts: 2.5-year follow-up. Compr. Psychiatry 1987, 28, 3-13. [CrossRef]

37. McLellan, A.T.; Luborsky, L.; Woody, G.E.; O’Brien, C.P.; Kron, R. Are the "addiction-related" problems of substance abusers really related? J. Nerv. Ment. Dis. 1981, 169, 232-239. [CrossRef]

38. Rounsaville, B.J.; Kosten, T.R.; Kleber, H.D. The antecedents and benefits of achieving abstinence in opioid addicts: A 2.5-year follow-up study. Am. J. Drug Alcohol Abuse 1987, 13, 213-229. [CrossRef]

39. Rounsaville, B.J.; Tierney, T.; Crits-Christoph, K.; Weissman, M.M.; Kleber, H.D. Predictors of outcome in treatment of opiate addicts: Evidence for the multidimensional nature of addicts' problems. Compr. Psychiatry 1982, 23, 462-478. [CrossRef]

40. Khantzian, E.J. The self-medication hypothesis of substance use disorders: A reconsideration and recent applications. Harv. Rev. Psychiatry 1997, 4, 231-244. [CrossRef]

41. Hunt, G.M.; Azrin, N.H. A community-reinforcement approach to alcoholism. Behav. Res. Ther. 1973, 11, 91-104. [CrossRef]

(C) 2019 by the authors. Licensee MDPI, Basel, Switzerland. This article is an open access article distributed under the terms and conditions of the Creative Commons Attribution (CC BY) license (http://creativecommons.org/licenses/by/4.0/). 